\title{
Biogenic Amine Neurotransmitter Response to Morphine in the Anterior Cingulate Cortex Predicts Propensity for Acquiring Self-Administration and the Intensity of the Withdrawal Syndrome
}

\author{
Maria Trigub' ${ }^{1}$, Vladinir Kudrin², Valentina Bashkatova1, Petr Klodt'², Sergey Sudakov \\ ${ }^{1}$ P. K. Anokhin Research Institute of Normal Physiology, Moscow, Russia \\ ${ }^{2}$ V. V. Zakusov Research Institute of Pharmacology, Moscow, Russia \\ Email: v.bashkatova@nphys.ru
}

Received 18 August 2014; revised 17 September 2014; accepted 9 October 2014

Copyright (C 2014 by authors and Scientific Research Publishing Inc.

This work is licensed under the Creative Commons Attribution International License (CC BY). http://creativecommons.org/licenses/by/4.0/

(c) (i) Open Access

\section{Abstract}

Individual differences in behavioral characteristics or initial responses to abused drugs had been recently demonstrated to have predictive value in the propensity of later abuse. The research described here was initiated to determine the initial response of rats to administration of morphine if the physiological response has predictive value for the propensity of the animals to later selfadministration. The initial response of extracellular fluid levels of the biogenic monoamine neurotransmitters in the anterior cingulate cortex (aCC) was assessed in drug rats with in vivo microdialysis following administration of morphine. Rats that did not acquire morphine self-administration (NSA) had higher baseline levels of aCC extracellular fluid levels of dopamine (DA) and 3,4-dihydroxyphenylacetic acid (DOPAC) than animals that developed stable morphine self-administration (SA). However, the response independent administration of morphine resulted in a dramatic increase in (DA) in aCC in the SA group, while the morphine injection in the NSA rats increased extracellular fluid levels of noradrenaline (NA). It is possible that these differences might be related to the development of physical dependence. Therefore, the development of physical dependence was observed in these animals. There was no relationship between the propensity to self-administration morphine and the development of physical dependence. Rats that showed the highest withdrawal scores had lower extracellular fluid levels of serotonin (5-HT) compared to rats showing low withdrawal scores. Thus, monoamine neuronal innervations of the aCC respond to an initial dose of morphine that is predictive of the later propensity to self-administration and the resistance and predisposition to the formation of opiate dependence, but there is no relation- 
ship between these two indices in individual animals. These data add to a growing body of evidence for the involvement of neuronal systems in the aCC in the actions of opiates.

\author{
Keywords
}

\author{
Anterior Cingulate Cortex, Dopamine, Serotonin, In Vivo Microdialysis, Intravenous \\ Self-Administration of Morphine
}

\title{
1. Introduction
}

There is a significant degree of variability in the vulnerability of individuals to escalate drug intake from recreational use to abuse and data from the animal laboratory has identified mechanisms that may be responsible for some of these differences. A relationship between emotionality and the acquisition of drug self-administration was demonstrated in the animal laboratory. It has been shown that stress induced locomotor activity [1] or corticosterone levels [2] was predictive of individual variability to a later response to amphetamine in rats. The locomotor response to a novel environment appears to have predictive value in morphine intake in rats during the first five days of acquisition of self-administration [3]. It was suggested that strain differences in the structure of pyramidal cells in certain cortical areas might represent an anatomical substrate for the distinct vulnerability to the reinforcing effects of morphine exhibited by Fischer 344 and Lewis rats in operant self-administration paradigms [4]. In addition, emotionality in the lick suppression test is correlated with later morphine self-administration in rats [5].

The anterior cingulate cortex (aCC) is a component of the brain limbic system that is thought to participate in the neuronal mechanisms underlying emotional behavior [6] [7]. In addition, the aCC appears to be involved in the actions of cocaine [8]-[10] and opiates [11]-[13]. Furthermore, the cingulate cortex has been shown to be hyperactive and activation to be positively correlated with the desire for the drug during craving in drug abusers [14] [15]. The destruction of rat cingulate cortex has been shown to reduce sensitivity to the positive reinforcing effects of morphine, delay the development of dependence and attenuate the withdrawal syndrome without altering the analgesic properties or the development of tolerance [16]. The aCC contains terminals of the monoamine neurotransmitters, in particular, dopamine (DA) innervations from the ventral tegmental area, noradrenaline (NA) innervations from the locus coeruleus and serotonin (5-HT) innervations from the raphe nuclei [17] [18]. The role of these monoaminergic innervations of the aCC in drug self-administration is not clear still now. The experiments described here were designed to assess the relationship between the effects of morphine on the extracellular fluid levels of DA, NA and 5-HT in the aCC in rats and the propensity for the later acquisition of morphine self-administration and the development of physical dependence.

\section{Materials and Methods}

The experiments were performed on male Wistar rats obtained from the Stolbovaja nursery (Russian Academy of Medical Sciences). The animals (basal weight 240 - 270 g) were housed in individually ventilated cages (4 rats per cage) under a 12:12-h light-dark cycle with free access to food and water.The experiment was conducted in accordance with the "Rules of Studies on Experimental Animals" (approved by the Ethics Committee of the P. K. Anokhin Institute of Normal Physiology; protocol No. 1, 3.09.2005), the requirements of the World Society for the Protection of Animals (WSPA), and the European Convention for the Protection of Experimental Animals.

Surgical procedures: The rats were anesthetized (100 mg/kg ketamine (Moscow Endocrine Plant) and 100 $\mathrm{mg} / \mathrm{kg}$ xylazine ("Alfasan International B.V”, Netherlands), the scull was exposed and a hole drilled and a CMA/12 siliconized plastic guide cannula (CMA/microdialysis, Sweden) stereotaxically implanted into the right anterior cingulate cortex using coordinates A + 0.5; L - 0.5; H - 1.0 [19]. Two-component synthetic catheters were implanted into the jugular veins of each animal with the tip of the catheter positioned near the origin of the anterior vena cava. The intravenous portion of the catheter was 25-mm of silastic tubing (O.D. $1.2 \mathrm{~mm}$, Dow Corning Corp., USA) and the remaining portion 55-mm of vinyl tubing (O.D. $1.0 \mathrm{~mm}$ - Dural Plastic and Engineering, Australia) connected to the intravenous tubing with an adapter (Small Parts Inc., USA). The free end of 
the vinyl tubing was fixed to the skin on the back of the neck. The rats were maintained in individual boxes with free access to food and water for 3 days to recover from the major effects of surgery.

Microdialysis procedures: A CMA/12 microdialysis probe (CMA/microdialysis, Sweden) was inserted through the implanted guide cannula and the animals placed into experimental chambers (Lafayette Instruments Inc., USA) for a 300 minute session. The microdialysis probe was a vinyl tube covered with a stainless steel jacket with a diameter of $0.64 \mathrm{~mm}$. The other tip of the tube which had a diameter of $0.5 \mathrm{~mm}$, protruded $2 \mathrm{~mm}$ beyond the previously implanted plastic guide cannula. The microdialysis probe was a semipermeable membrane with pores permitting molecules with a molecular weight $<6000$ Da to freely pass from the perineuronal space into the probe. The inlet of the tube was connected through a swivel to a precision pump (Harvard Apparatus, USA) and the outlet was placed into a polypropylene vial for collecting the microdialysate samples. The microdialysis probe was inserted into the guide cannula in the anterior cingulate cortex and perfused with artificial cerebrospinal fluid at a rate of $0.6 \mu \mathrm{l} / \mathrm{min}$ for $2 \mathrm{~h}$ for stabilization. This time period was previously shown to result in stabilization of the levels of DA, NA and 5-HT in the microdialysate. Two control samples were then collected (45 min each) and the rats then administered $2 \mathrm{mg} / \mathrm{kg}$ of morphine hydrochloride (Moscow Endocrine Plant) (i.p), a dose, previously shown to induce positive conditioning without significant CNS depression [20][22], and then two additional $45-\mathrm{min}$ microdialysate samples collected and the samples stored at $-70^{\circ} \mathrm{C}$ until analysis.

High pressure liquid chromatography procedure: The microdialasates were thawed and immediately injected into a high-performance liquid chromatograph (HPLC) for measurement of the content of dopamine, norepinephrine, serotonin, and their metabolites: 5-hydroxyindoleacetic acid (5HIAA) and homovanillic acid (HVA). Two microliters of $0.4 \mathrm{M} \mathrm{HClO}_{4}$ was added to the samples to minimize photodegradation of the catecholamines and an isocratic HPLC system was used that consisted of a Gilson 307 pump (Gilson, USA) and an LC-4B electrochemical detector (Bioanalytical Systems, USA) with a $20 \mu$ injector loop. Separation of the catecholamines was accomplished using a HYPERSIL ODS C-18 analytic column $(4 \mu, 4.6 \times 100 \mathrm{~mm}$, USA). The mobile phase consisted of $0.1 \mathrm{M}$ citrate-phosphate buffer containing $1.1 \mathrm{mM}$ octanesulfonic acid, $0.1 \mathrm{mM}$ EDTA and $9 \%$ acetonitrile (Sigma, $\mathrm{pH} 3.0$ ) at $23^{\circ} \mathrm{C} \pm 1{ }^{\circ} \mathrm{C}$ and $0.5 \mathrm{ml} / \mathrm{min}$ flow rate $(\mathrm{P}=170 \mathrm{Bar}$ ). The LC-4B electrochemical detector utilized a glassy carbon electrode $(+0.85 \mathrm{~V})$ and a $\mathrm{Ag} / \mathrm{AgCl}$ reference electrode. The chromatograms were recorded and processed using an analog-digital converter supplied with MultiKhrom1.5 software (Ampersand, Russia). The second 45 minute control sample of each animal was considered the 100\% baseline level to which the experimental data was compared to minimize potential carryover effects of the probe insertion.

Morphine self-administration procedure: On the next day following the assessment of the i.p. injection of morphine, the rats were placed into experimental chambers to assess the acquisition of intravenous morphine self-administration. The free end of the intravenous catheter was connected through a swivel to a syringe containing morphine solution in a syringe pump. The rats were given the opportunity to press a lever positioned on the right sight of the wall of the chamber which resulted in the infusion of $100 \mu \mathrm{g}$ morphine hydrochloride in $0.05 \mathrm{ml}$ of isotonic $\mathrm{NaCl}$ through the intravenous catheter. An additional lever was located on the left side of the wall and was inactive. The injection was followed by a $17-\mathrm{sec}$ time out period during which the stimulus light above the active lever was extinguished and lever presses had no programmed consequences. The stimulus light was then again illuminated and the lever activated for further responding maintained by morphine infusion. Daily 60 minutesself-administration sessions occurred over the next 10 days to assess the acquisition and maintenance of intravenous morphine self-administration with the number of infusions and lever presses recorded. The monoamine levels in microdialysates of the aCC after the initial response independent administration of morphine were compared between animals that developed stable morphine self-administration during this period $(n=7)$ with those that did not $(n=8)$. The rats were separated into two groups, one of which included those that developed stable intravenous morphine self-administration (SA). The criterion for inclusion in this group was the development of stable self-administration of morphine on a fixed ratio 3 schedule during three successive sessions. Rats included in the other group did not self-administer morphine (NSA) and did not press the active lever during any of the last three sessions. Animals in the SA group were sensitivity to alterations in the dose of morphine available with increased self-administration when the dose was decreased (50 $\mu \mathrm{g} /$ infusion) and decreased self-administration when the dose was increased (200 $\mu \mathrm{g} /$ infusion). Neither SA nor NSA rats pressed the inactive lever during last five days of self-administration. Data were analyzed using t-test for unpaired variables and the differences considered significant at a $\mathrm{p}<0.05$. 
Assessment of physical dependence: The final stage of the experiment was initiated the next day following the tenth day of self-administration and involved the assessment of the level of physical dependence to morphine. The rats received morphine hydrochloride in increasing doses (from 10 to $60 \mathrm{mg} / \mathrm{kg}$, i.v.) twice a day with a 12 hour inter administration interval for 8 days. Six hours after the last injection, the withdrawal syndrome was precipitated by the administration of the opioid receptor antagonist naloxone $(1 \mathrm{mg} / \mathrm{kg}$, i.p.). Ten minutes after the administration of naloxone the rats were placed into a computerized open field system and the signs of abstinence (shakes, respiratory disturbances, ptosis, cramps, tooth-grinding, and diarrhea) were recorded. The total abstinence score and individual incidence of these signs in each rat were evaluated. The rats were separated again into two groups based upon the degree of physical dependence. One group included rats that displayed a severe withdrawal syndromes (total withdrawal score of 8 - 10) and the other groups included rats more resistant to the development of physical dependence (total withdrawal score of 1 - 4). The levels of the monoamine neurotransmitters and metabolites assessed with the initial injection of morphine in microdialysates from the anterior cingulate cortex were compared between the two groups as previously done with the propensity to self-administer. Data were analyzed using t-test for unpaired variables and the differences considered significant at a $\mathrm{p}$ $<0.05$.

\section{Results}

\section{Acquisition of Morphine Self-administration}

Response independent administration of morphine did not alter the concentration of the monoamine neurotransmitters or metabolites compared to baseline levels (Figure 1), when the data were segregated based upon the propensity of each rat to acquire morphine self-administration, significant differences became apparent. Significant difference between baseline parameters of DA metabolism was detected between the SA and NSA rats. DA and DOPAC in the NSA rats were higher than in the SA animals. In contrast, baseline NA and 5-HT and their metabolites did not differ between these two groups (Table 1). Although there were no significant differences in DA and DOPAC between the two baseline samples for individual animals, the content of the test substances in the second baseline sample was used for each animal as baseline which was then compared with the values obtained after the administration of morphine. The response independent administration of morphine resulted in a 300\%+ increase in DA only in the animals that later acquired self-administration (Figure 2). In contrast, the morphine injection in the NSA rats increased NA, while there were no changes in 5-HT in either group.

Physical Dependence

There was no correlation between the propensity to acquire morphine self-administration and the severity of the withdrawal syndrome after the development of physical dependence. In some rats, self-administration rapidly developed, but the withdrawal syndrome was mild. Other rats acquired self-administration and physical dependence and while some did not yet demonstrated a severe withdrawal syndrome. When microdialysis data was evaluated for the rats with the highest withdrawal scores (withdrawal score $7-10$, HW), lower 5-HT was seen compared to rats showing low withdrawal scores (withdrawal score 1 - 4, LW) (Figure 3). Neither of the HW or LW groups showed changes in the NA while DA tended to increase in both groups 45 min after the test morphine injection.

\section{Discussion}

The brain mechanisms underlying the perception of the positive reinforcing effect of drugs of abuse are thought to be closely related to activity of the brain mesocorticolimbic DA neurons. The administration of opiates to rats has been shown to increase DA release from nerve terminals in the nucleus accumbens [23]. In addition, morphine does not produce a positive reinforcing effect in knockout mice lacking the dopamine $\mathrm{D}_{2}$ receptor [24] [25]. Both increases [26] and decreases [27] in nucleus accumbens extracellular fluid levels of DA have been reported in rats self-administering heroin while morphine administration has been reported to increase the release of DA in basal parts of forebrain [28] and increase DA metabolism in the aCC [29] [30]. It has been postulated that a reduction of $\mathrm{D}_{2}$ receptors and a decrease in activity in the anterior cingulate gyrus and orbitofrontal cortex is one of the mechanisms through which DA abnormalities lead to compulsive drug administration and the lack of control over drug intake by addicts [31]. In the experiments presented here, no changes in the concentration of dopamine were observed in microdialysates of the aCC after response independent morphine administration in drug naive animals. However, when the data were analyzed based upon the propensity of later 
Table 1. Levels of dopamine, noradrenaline and serotonin and metabolites in microdialysate from the anterior cingulate cortex of rats acquiring (SA) and not acquiring (NSA) morphine self-administration.

\begin{tabular}{|c|c|c|c|c|c|c|c|c|c|c|c|c|}
\hline & \multicolumn{2}{|c|}{ DA } & \multicolumn{2}{|c|}{ DOPAC } & \multicolumn{2}{|c|}{ HVA } & \multicolumn{2}{|c|}{ NA } & \multicolumn{2}{|c|}{$5 \mathrm{HT}$} & \multicolumn{2}{|c|}{ 5HIAA } \\
\hline & $\begin{array}{c}0-45 \\
\min \end{array}$ & $\begin{array}{c}45-90 \\
\min \end{array}$ & $\begin{array}{c}0-45 \\
\min \end{array}$ & $\begin{array}{c}45-90 \\
\min \end{array}$ & $\begin{array}{c}0-45 \\
\min \end{array}$ & $\begin{array}{c}45-90 \\
\min \end{array}$ & $\begin{array}{c}0-45 \\
\min \end{array}$ & $\begin{array}{c}45-90 \\
\min \end{array}$ & $\begin{array}{c}0-45 \\
\min \end{array}$ & $\begin{array}{c}45-90 \\
\min \end{array}$ & $\begin{array}{c}0-45 \\
\min \end{array}$ & $\begin{array}{c}45-90 \\
\min \end{array}$ \\
\hline $\begin{array}{c}\text { SA } \\
n=7\end{array}$ & $\begin{array}{c}24.952 \pm \\
5.97\end{array}$ & $\begin{array}{c}18.872 \pm \\
3.98\end{array}$ & $\begin{array}{c}3.191 \pm \\
0.689\end{array}$ & $\begin{array}{c}3.544 \pm \\
0.587\end{array}$ & $\begin{array}{c}4.435 \pm \\
0.69\end{array}$ & $\begin{array}{c}2.910 \pm \\
0.72\end{array}$ & $\begin{array}{c}50.142 \pm \\
15.213\end{array}$ & $\begin{array}{c}36.824 \pm \\
10.23\end{array}$ & $\begin{array}{c}1.829 \pm \\
0.92\end{array}$ & $\begin{array}{c}1.983 \pm \\
0.88\end{array}$ & $\begin{array}{c}0.62 \pm \\
0.182\end{array}$ & $\begin{array}{c}0.406 \pm \\
0.1971\end{array}$ \\
\hline $\begin{array}{l}\text { NSA } \\
n=8\end{array}$ & $\begin{array}{c}41.242 \pm \\
6.88\end{array}$ & $\begin{array}{c}39.778 \pm \\
4.77\end{array}$ & $\begin{array}{c}9.272 \pm \\
1.487\end{array}$ & $\begin{array}{c}7.427 \pm \\
1.222\end{array}$ & $\begin{array}{c}5.941 \pm \\
1.097\end{array}$ & $\begin{array}{c}4.678 \pm \\
0.98\end{array}$ & $\begin{array}{c}35.173 \pm \\
12.234\end{array}$ & $\begin{array}{c}24.618 \pm \\
11.021\end{array}$ & $\begin{array}{c}1.985 \pm \\
0.88\end{array}$ & $\begin{array}{c}1.774 \pm \\
1.101\end{array}$ & $\begin{array}{c}1.151 \pm \\
0.58\end{array}$ & $\begin{array}{c}1.447 \pm \\
0.428\end{array}$ \\
\hline
\end{tabular}

Values are means and standard error of the means in pmol/ml. Levels of significance between mean assessed with Students $t$ tests were: $\mathrm{p}<0.05$.

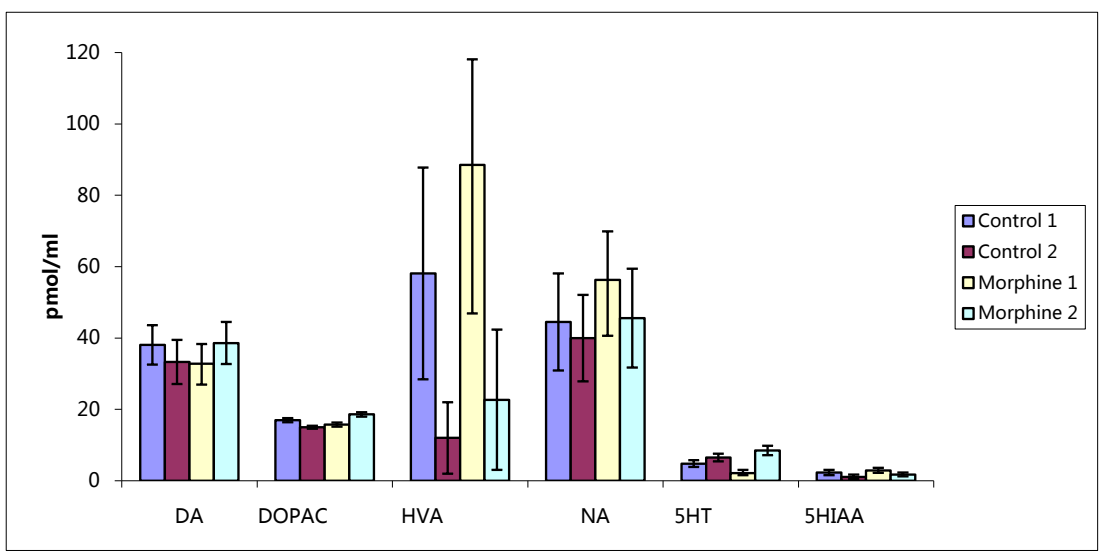

Figure 1. Levels of monoamine neurotransmitters and metabolites in microdialysates from the anterior cingulated cortex in two 45 minute samples in control (control 1 and 2) and after morphine (morphine 1 and 2) administration (n=20).

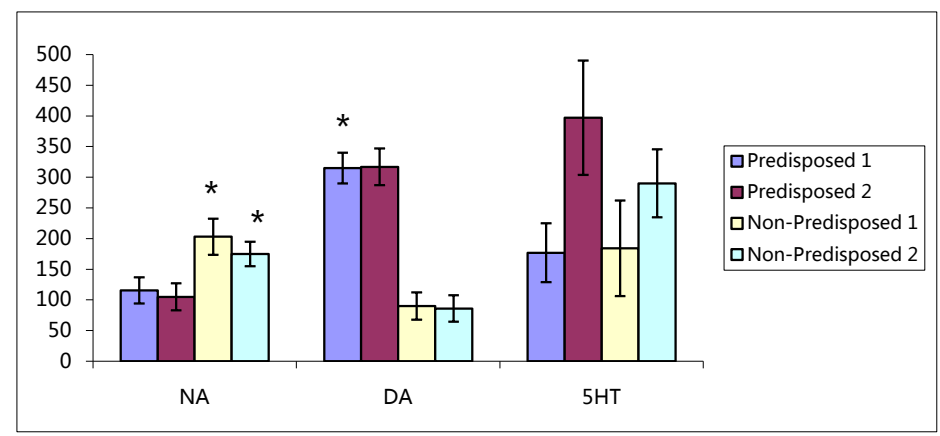

Figure 2. Changes of levels of noradrenaline (NA), dopamine (DA) and serotonin in microdialysates from the anterior cingulated cortex after response independent morphine administration in rats acquiring $(\mathrm{SA}, \mathrm{n}=7)$ and not acquiring (NSA, $\mathrm{n}=8$ ) morphine self-administration sample 1 and 2 . Y-axis- $\%$ of control. Values are means and standard errors of the means. Levels of significance between SA and NSA means assessed with Students t tests were: ${ }^{*} \mathrm{p}<0.05$.

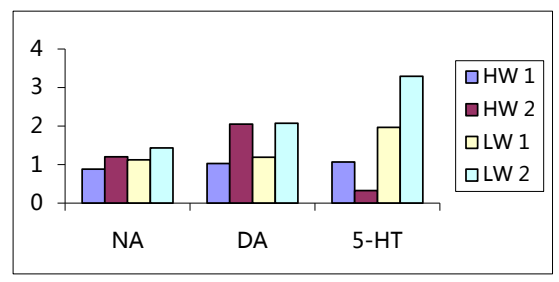

Figure 3. Changes of levels of noradrenaline (NA), dopamine (DA) and serotonin in microdialysates of the anterior cingulated cortex of high withdrawal $(\mathrm{HW}, \mathrm{n}=7)$ and low withdrawal $(\mathrm{LW}, \mathrm{n}=7)$ rats after response independent morphine administration in sample 1 and 2. Y-axis-\% of control. Values are means and standard errors of the means. Levels of significance between HV and LW means assessed with Students t tests were: ${ }^{*} \mathrm{p}<0.05$. 
acquisition of intravenous self-administration, a significant lower baseline level of DA was seen in the extracellular fluid and a significant greater response to the administration of morphine was seen in the animals that acquired self-administration. Thus, the rats that later demonstrated a reinforcing effect of morphine by acquisition of self-administration, showed an elevated effect to response independent morphine on DA release from nerve terminals in the aCC. These animals demonstrated a significantly lower initial DA and DOPAC in the aCC, which suggests decreased dopamine metabolism in this brain region which is consistent with the hypothesis that individuals with low activity of the brain DA system are predisposed to the use of psychoactive drugs, while abused drugs may "normalize" the function of this system [32] [33].

The increase in NA release from nerve terminals in the aCC of rats that did not acquire morphine self-administration may also be important. The role of NA in the mechanisms of the negative affective components of the withdrawal syndrome in morphine-dependent individuals is well established [34]. However, the data concerning changes in extracellular NA content in brain structures after a single morphine administration are contradictory. Both a morphine-induced decrease in NA content in rat prefrontal cortex [35] has been reported while others found that NA release in this brain area was necessary for the perception of the rewarding effect of morphine [36]. In addition, mice lacking dopamine beta-hydroxylase (DBH), an enzyme critical for NA synthesis, did not develop a morphine-induced conditioned place preference [37]. Viral restoration of DBH expression in the nucleus tractus solitarius, but not in the locus coeruleus, restored perception of morphine reward in these animals. The observed increase of NA in rats that did not acquire morphine self-administration and the absence of this increase in rats that did, does not support the relationships between this process and the positive reinforcing effects of morphine. More likely, NA release in the cingulate cortex may be involved in the negative sensations that occur after the administration of morphine in some individuals. The previously reported suppression of the perception of the positive reinforcing effect of morphine after destruction of the aCC could result from a decreased response of DA innervations of this region and not from modulations in NA innervations since the rats not acquiring dependence to morphine were excluded from these morphine self-administration experiments [38].

The initial response of 5-HT innervations of the aCC to morphine was predictive of the intensity of the withdrawal syndrome. Rats showing the highest withdrawal scores had significantly lower 5-HT in the aCC with response independent morphine administration than rats showing low or moderate withdrawal scores. The increase of 5-HT in the aCC after response independent morphine administration was observed only in animals that were more resistant to the formation of physical dependence and suggests that serotonergic innervations of this region may have some role in the withdrawal syndrome.

\section{Conclusions}

The major findings from this study are that the initial response of aCC DA neurons in drug naive rats to a response independent infusion of morphine is predictive of the likelihood of later acquisition of morphine selfadministration. Significantly lower baseline DA were in drug naive rats that later acquired self-administration than in rats that did not. In addition, these rats showed significant increases in DA in response to morphine compared to the NSA group. These baseline levels reflect the initial effects of the response independent administration of the same dose of morphine to rats with similar drug naive histories.

In summary, monoamine neuronal innervations of the aCC appear to have a significant role in the mechanisms underlying the propensity to self-administer morphine and the resistance and predisposition to the formation of opiate dependence.

\section{References}

[1] Orsini, C., Buchini, F., Piazza, P.V., Puglisi-Allegra, S. and Cabib, S. (2004) Susceptibility to Amphetamine-Induced Place Preference Is Predicted by Locomotor Response to Novelty and Amphetamine in the Mouse. Psychopharmacology (Berl.), 172, 264-270. http://dx.doi.org/10.1007/s00213-003-1647-z

[2] Marinelli, M. and Piazza, P.V. (2002) Interaction between Glucocorticoid Hormones, Stress and Psychostimulant Drugs. European Journal of Neuroscience, 16, 387-394. http://dx.doi.org/10.1046/j.1460-9568.2002.02089.x

[3] Ambrosio, E., Goldberg, S.R. and Elmer, G.I. (1995) Behavior Genetic Investigation of the Relationship between Spontaneous Locomotor Activity and the Acquisition of Morphine Self-Administration Behavior. Behavioural Pharmacology, 6, 229-237. http://dx.doi.org/10.1097/00008877-199504000-00003

[4] Ballesteros-Yanez, I., Ambrosio, E., Pérez, J., Torres, I., Miguéns, M., García-Lecumberri, C. and DeFelipe, J. (2008) 
Morphine Self-Administration Effects on the Structure of Cortical Pyramidal Cells in Addiction-Resistant Rats. Brain Research, 16, 61-72. http://dx.doi.org/10.1016/j.brainres.2008.06.128

[5] Sudakov, S.K., Goldberg, S.R., Borisova, E.V., Surkova, L.A., Turina, I.V., Rusakov, D.Ju. and Elmer, G.I. (1993) Differences in Morphine Reinforcement Property in Two Inbred Rat Strains: Associations with Cortical Receptors, Behavioral Activity, Analgesia and the Cataleptic Effects of Morphine. Psychopharmacology (Berl), 112, 183-188. http://dx.doi.org/10.1007/BF02244908

[6] Cohen, R.A., Paul, R., Zawacki, T.M., Moser, D.J., Sweet, L. and Wilkinson, H. (2001) Emotional and Personality Changes Following Cingulotomy. Emotion, 1, 38-50. http://dx.doi.org/10.1037/1528-3542.1.1.38

[7] Alexopoulos, G.S., Gunning-Dixon, F.M., Latoussakis, V., Kanellopoulos, D. and Murphy, C.F. (2008) Anterior Cingulate Dysfunction in Geriatric Depression. International Journal of Geriatric Psychiatry, 23, 347-355. http://dx.doi.org/10.1002/gps.1939

[8] Risinger, R.C., Salmeron, B.J., Ross, T.J., Amen, S.L., Sanfilipo, M., Hoffmann, R.G., Bloom, A.S., Garavan, H. and Stein, E.A.(2005) Neural Correlates of High and Craving During Cocaine Self-Administration Using BOLD fMRI. Neuroimage, 26, 1097-1108. http://dx.doi.org/10.1016/j.neuroimage.2005.03.030

[9] Sinha, R., Lacadie, C., Skudlarski, P., Fulbright, R.K., Rounsaville, B.J., Kosten, T.R. and Wexler, B.E. (2005) Neural Activity Associated with Stress-Induced Cocaine Craving: A Functional Magnetic Resonance Imaging Study. Psychopharmacology (Berl), 183, 171-180.

[10] Pockros, L.A., Pentkowski, N.S., Swinford, S.E. and Neisewander, J.L. (2011) Neisewander Blockade of 5-HT2A receptors in the Medial Prefrontal Cortex Attenuates Reinstatement of Cue-Elicited Cocaine-Seeking Behavior in Rats. Psychopharmacology (Berl), Author Manuscript; Available in PMC 2011 April 7. http://dx.doi.org/10.1007/s00213-005-0147-8

[11] Trafton, C.L. and Marques, P.R. (1971) Effects of Septal Area and Cingulate Cortex Lesions on Opiate Addiction Behavior in Rats. Journal of Comparative and Physiological Psychology, 75, 277-285. http://dx.doi.org/10.1037/h0030810

[12] Tzschentke, T.M. and Schmidt, W.J. (1999) Functional Heterogeneity of the Rat Medial Prefrontal Cortex: Effects of Discrete Subarea-Specific Lesions on Drug-Induced Conditioned Place Preference and Behavioral Sensitization. European Journal of Neuroscience, 11, 4099-4109. http://dx.doi.org/10.1046/j.1460-9568.1999.00834.x

[13] Su, Y.L., Huang, J., Wang, N., Wang, J.Y. and Luo, F. (2012) The Effects of Morphine on Basal Neuronal Activities in the Lateral and Medial Pain Pathways. Neuroscience Letters, 525, 173-178.

[14] Volkov, N.D., Fowler, J.S. and Wang, G.J. (2002) Role of Dopamine in Drug Reinforcement and Addiction in Humans: Results from Imaging Studies. Behavioral Pharmacology, 13, 355-366. http://dx.doi.org/10.1097/00008877-200209000-00008

[15] Jasinska, A.J., Stein, E.A., Kaiser, J., Naumer, M.J. and Yalachkov, Y. (2014) Factors Modulating Neural Reactivity to Drug Cues in Addiction: A Survey of Human Neuroimaging Studies. Neuroscience \& Biobehavioral Reviews, 38, 1-16. http://dx.doi.org/10.1016/j.neubiorev.2013.10.013

[16] Sudakov, S.K., Rusakova, I.V., Trigub, M.N., Shakhmatov, V.Y., Kozel, A.I. and Smith, G.E. (2004) Effect of Destruction of Gyrus Cinguli in Rat Brain on the Development of Tolerance to the Analgesic Effect of Morphine and Physical Dependence on Morphine. Bulletin of Experimental Biology and Medicine, 138, 479-481. http://dx.doi.org/10.1007/s10517-005-0075-y

[17] Dahlstrom, A. and Fuxe, K. (1964) Localization of Monoamines in the Lower Brain Stem. Experientia, 20, $398-399$. http://dx.doi.org/10.1007/BF02147990

[18] Chandler, D.J., Lamperski, C.S. and Waterhouse, B.D. (2013) Identification and Distribution of Projections from Monoaminergic and Cholinergic Nuclei to Functionally Differentiated Subregions of Prefrontal Cortex. Brain Research, 19, 38-58. http://dx.doi.org/10.1016/j.brainres.2013.04.057

[19] Paxinos, G. and Watson, C. (1986) The Rat Brain in Stereotaxic Coordinates. Second Edition, Academic Press, Waltham.

[20] Gong, Y.X., Lv, M., Zhu, Y.P., Zhu, Y.Y., Wei, E.Q., Shi, H., Zeng, Q.L. and Chen, Z. (2007) Endogenous Histamine Inhibits the Development of Morphine-Induced Conditioned Place Preference. Acta Pharmacologica Sinica, 28, 10-18. http://dx.doi.org/10.1111/j.1745-7254.2007.00470.x

[21] Mucha, R.F. and Herz, A. (1985) Motivational Properties of Kappa and Mu Opioid Receptor Agonists Studied with Place and Taste Preference Conditioning. Psychopharmacology, 86, 274-280. http://dx.doi.org/10.1007/BF00432213

[22] Spyraki, C., Nomikos, G.G., Galanopoulou, P. and DaÏfotis, Z. (1988) Drug-Induced Place Preference in Rats with 5,7-Dihydroxytryptamine Lesions of the Nucleus Accumbens. Behavioural Brain Research, 29, 127-134. http://dx.doi.org/10.1016/0166-4328(88)90060-5 
[23] Koob, G.F. and Le Moal, M. (2001) Drug Addiction, Dysregulation of Reward and Allostasis. Neuropsychopharmacology, 24, 97-129. http://dx.doi.org/10.1016/S0893-133X(00)00195-0

[24] Maldonado, R., Saiardi, A. and Valverde, O. (1997) Absence of Opiate Rewarding Effects in Mice Lacking Dopamine D2 Receptors. Nature, 388, 586-589. http://dx.doi.org/10.1038/41567

[25] Elmer, G.I., Pieper, J.O., Levy, J., Rubinstein, M., Low, M.L., Grandy, D.K. and Wise, R.A. (2005) Brain Stimulation and Morphine Reward Deficits in Dopamine D2 Receptor-Deficient Mice. Psychopharmacology, 182, 33-44. http://dx.doi.org/10.1007/s00213-005-0051-2

[26] Wise, R.A., Leone, P., Rivest, A. and Leeb, K. (1995) Elevations of Nucleus Accumbens Dopamine and DOPAC Levels during Intravenous Heroin Self-Administration. Synapse, 21, 140-148. http://dx.doi.org/10.1002/syn.890210207

[27] Hemby, S.E., Martin, T.J., Co, C., Dworkin, S.I. and Smith, J.E. (1995) The Effects of Intravenous Heroin Administration on Extracellular Nucleus Accumbens Dopamine Concentrations as Determined by in Vivo Microdialysis. Journal of Pharmacology and Experimental Therapeutics, 273, 591-598.

[28] Moleman, P. and Bruinvels, J. (1979) Effect of Morphine on Dopaminergic Neurons in the Rat Basal Forebrain and Striatum. Journal of Neural Transmission, 46, 225-237. http://dx.doi.org/10.1007/BF01250788

[29] Kim, H.S., Iyengar, S. and Wood, P.L. (1986) Opiate Actions on Mesocortical Dopamine Metabolism in the Rat. Life Sciences, 39, 2033-2036. http://dx.doi.org/10.1016/0024-3205(86)90327-9

[30] Kim, H.S., Iyengar, S. and Wood, P.L. (1987) Reversal of the Actions of Morphine on Mesocortical Dopamine Metabolism in the Rat by the Kappa Agonist MR-2034: Tentative Mu-2 Opioid Control of Mesocortical Dopaminergic Projections. Life Sciences, 41, 1711-1715. http://dx.doi.org/10.1016/0024-3205(87)90598-4

[31] Volkov, N.D., Fowler, J.S., Wang, G.J. and Goldstain, R.Z. (2002) Role of Dopamine, the Frontal Cortex and Memory Circuits in Drug Addiction: Insight from Imaging Studies. Neurobiology of Learning and Memory, 78, 610-624. http://dx.doi.org/10.1006/nlme.2002.4099

[32] Anokhina, I., Veretinskaja, A.G. and Vekshina, N.L. (2003) Functional Peculiarities of Dopamine System of Inbred Mice with High and Low Alcohol and Drug Craving. Questions of Addictions, 6, 62-69.

[33] Volkov, N.D., Fowler, J.S., Wang, G.J. and Swanson, J.M. (2004) Dopamine in Drug Abuse and Addiction: Results from Imaging Studies and Treatment Implications. Molecular Psychiatry, 9, 557-569. http://dx.doi.org/10.1038/sj.mp.4001507

[34] Watanabe, T., Nakagawa, T., Yamamoto, R., Maeda, A., Minami, M. and Satoh, M. (2003) Involvement of Noradrenergic System within the Central Nucleus of Amygdale in Naloxon-Precipitated Morphine Withdrawal-Induced Conditioned Place Aversion in Rats. Psychopharmacology, 170, 80-88. http://dx.doi.org/10.1007/s00213-003-1504-0

[35] Devoto, P., Flore, G., Pira, L., Dians, L. and Gessa, G.L. (2002) Co-Release of Noradrenaline and Dopamine in the Prefrontal Cortex after Acute Morphine and during Morphine Withdrawal. Psychopharmacology, 160, 220-224. http://dx.doi.org/10.1007/s00213-001-0985-y

[36] Ventura, R., Alcaro, A. and Puglisi-Allegra, S. (2005) Prefrontal Cortex Norepinephrine Release Is Critical for Morphine-Induced Reward, Reinstatement and Dopamine Release in the Nucleus Accumbence. Cerebral Cortex, 15, 18771886. http://dx.doi.org/10.1093/cercor/bhi066

[37] Olson, V.G., Heusner, C.L., Bland, R.J., During, M.J., Weinshenker, D. and Palmiter, R.D. (2006) Role of Noradrenergic Signaling by Nucleus Tractus Solitarius in Mediating Opiate Reward. Science, 311, 1017-1020. http://dx.doi.org/10.1126/science.1119311

[38] Sudakov, S.K., Rusakova, I.V., Trigub, M.M., Shahmatov, V.Y., Kozel, A.I. and Smith, J.E. (2005) Changes of Sensitivity to Morphine in Morphin-Dependent Rats after Laser Destruction of Prefrontal Cortex. Bulletin of Experimental Biology and Medicine, 141, 187-190. 


\section{Abbrevations}

aCC: Anterior cingulate cortex

CNS: Central Nervous System

DA: Dopamine

DBH: Dopamine beta-hydroxylase

DOPAC: 3,4-dihydroxyphenylacetic acid

HPLC: A high-performance liquid chromatography

HVA: homovanillic acid

HW: Rats with the highest withdrawal scores

LW: Rats with the low withdrawal scores

NA: Noradrenaline

NSA: Rats that did not acquire morphine self-administration

SA: Rats that developed stable morphine self-administration

5-HT: 5-hydroxytryptamine, serotonin

5HIAA: 5-hydroxyindoleacetic acid 
Scientific Research Publishing (SCIRP) is one of the largest Open Access journal publishers. It is currently publishing more than 200 open access, online, peer-reviewed journals covering a wide range of academic disciplines. SCIRP serves the worldwide academic communities and contributes to the progress and application of science with its publication.

Other selected journals from SCIRP are listed as below. Submit your manuscript to us via either submit@scirp.org or Online Submission Portal.
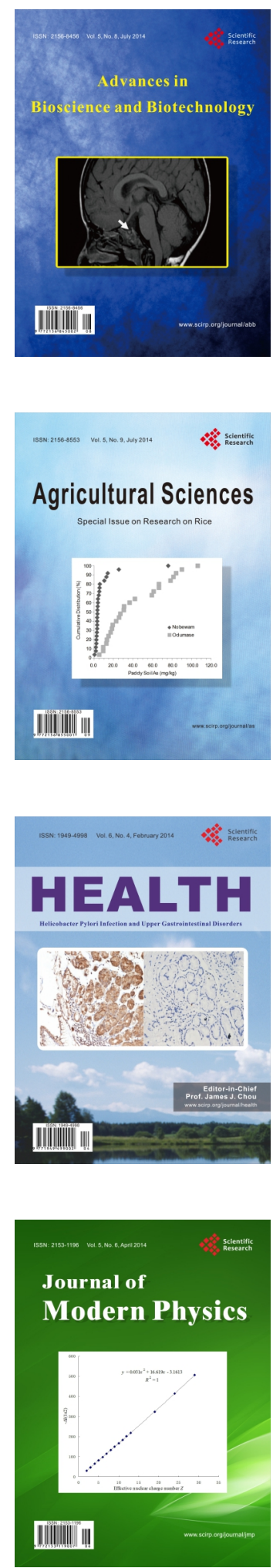
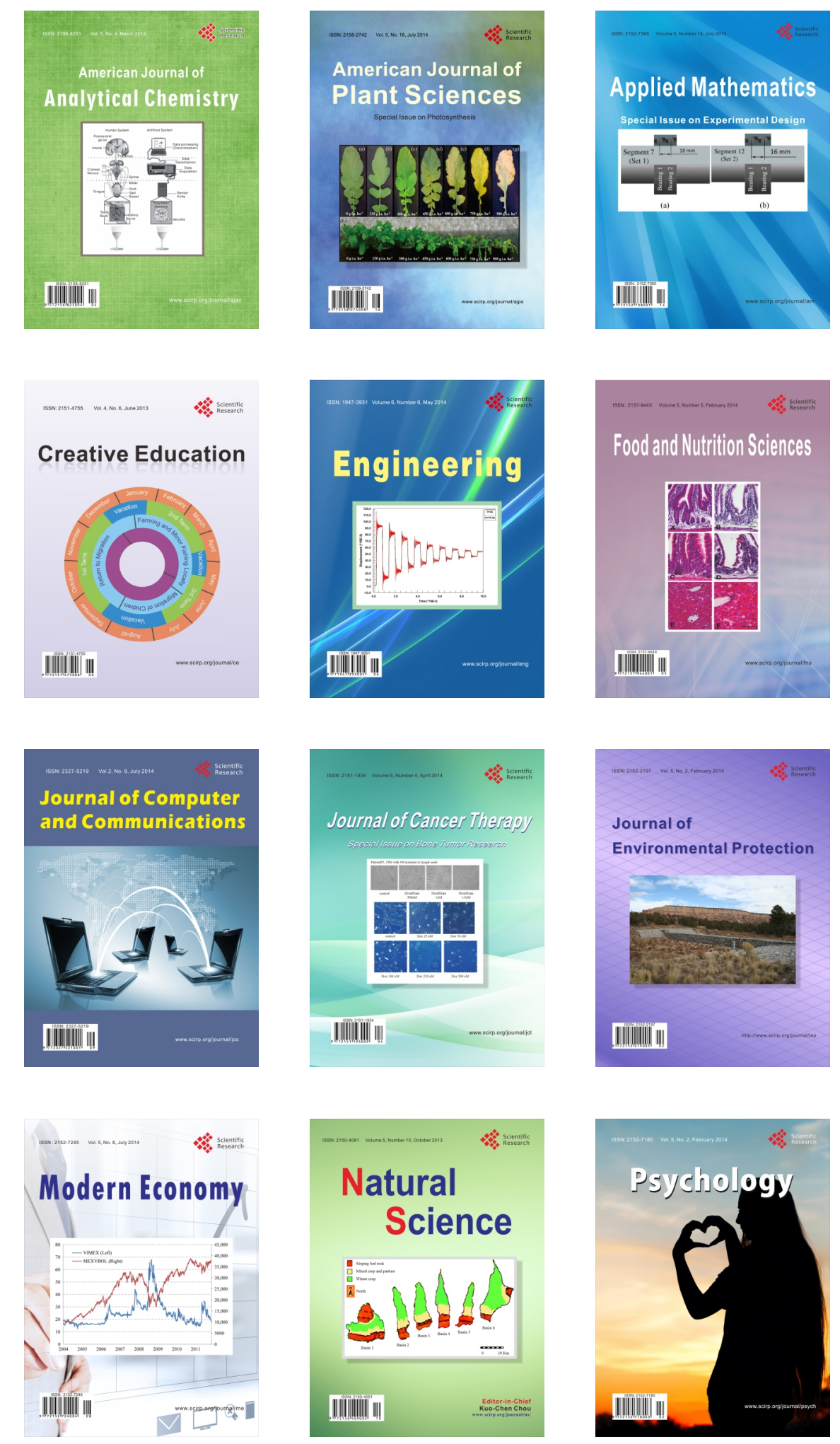